University of Nebraska - Lincoln

DigitalCommons@University of Nebraska - Lincoln

Faculty Publications, Department of Psychology

Psychology, Department of

2-14-2002

\title{
The Development of a Measure of Prosocial Behaviors for Late Adolescents
}

Gustavo Carlo

University of Nebraska-Lincoln, carlog@missouri.edu

Brandy A. Randall

University of Nebraska-Lincoln, Brandy.Randall@ndsu.edu

Follow this and additional works at: https://digitalcommons.unl.edu/psychfacpub

Part of the Psychiatry and Psychology Commons

Carlo, Gustavo and Randall, Brandy A., "The Development of a Measure of Prosocial Behaviors for Late Adolescents" (2002). Faculty Publications, Department of Psychology. 70.

https://digitalcommons.unl.edu/psychfacpub/70

This Article is brought to you for free and open access by the Psychology, Department of at DigitalCommons@University of Nebraska - Lincoln. It has been accepted for inclusion in Faculty Publications, Department of Psychology by an authorized administrator of DigitalCommons@University of Nebraska - Lincoln. 


\title{
The Development of a Measure of Prosocial Behaviors for Late Adolescents
}

\author{
Gustavo Carlo ${ }^{1}$ and Brandy A. Randall ${ }^{2}$
}

Submitted October 2000; accepted August 2001

\begin{abstract}
The correlates and structure of prosocial behaviors in late adolescents were examined using a newly constructed, multidimensional measure. In Study 1, 249 college students (145 women; $M$ age $=19.9$ years) were administered the Prosocial Tendencies Measure (PTM) which assesses 6 types of prosocial behaviors: altruistic, compliant, emotional, dire, public, and anonymous. Measures of sympathy, perspective taking, personal distress, social desirability, global prosocial behaviors, social responsibility, ascription of responsibility, vocabulary skills, and prosocial moral reasoning were also completed. Test-retest reliability and further validity of the PTM were demonstrated in Study 2 with a sample of 40 college students ( 28 women; $M$ age $=22.9$ years). Results from both studies yielded evidence of adequate reliability and validity of the PTM and support the notion of differentiated forms of helping.
\end{abstract}

KEY WORDS: prosocial behaviors; measurement; individual differences; behaviors.

\section{INTRODUCTION}

Research on the development and correlates of prosocial behaviors (i.e., behaviors intended to benefit others) has been an active field of study for the last three decades (Eisenberg and Fabes, 1998). Given the importance of understanding behaviors that benefit society, surprisingly few measures are available currently for studying prosocial behaviors, particularly in adolescence. While some measures do exist, these typically are characterized by a conceptualization of prosocial behavior as a global construct. However, investigators have shown that there are different types of prosocial behaviors and that these types are related differently to theoretically related constructs (see Batson, 1998; Eisenberg and Fabes, 1998; Staub, 1978). Furthermore, little is known regarding the characteristics of individuals with specific prosocial behavioral tendencies in late adolescence (Fabes et al., 1999). This study was designed primarily to examine the psychometric properties of a newly developed, mul- tidimensional measure of prosocial behaviors in late adolescence.

\section{Global versus Situation-Specific Measures of Prosocial Behavior}

Existing measures of prosocial behavior can be classified into one of at least two categories, those that assess global prosocial behavior or those that assess prosocial behavior in a specific situation. The most common measures of prosocial behaviors are those that are designed to assess global prosocial behaviors. Global prosocial behavior measures are defined as measures that assess personal tendencies to exhibit a number of prosocial behaviors across contexts and motives (e.g., Green et al., 1994; Johnson et al., 1989; Rushton et al., 1981; Weir and Duveen, 1981). A subtype of these measures are those that assess social competence or aspects of the broader construct of social competence (e.g., Ladd and Profilet, 1996; Rydell et al., 1997). The second type of

\footnotetext{
The authors greatly appreciate the assistance of April Brinkhoff, Scott Hunzeker, Pat Miner, Cindy Nash, Shawn Ryba, and Eileen Vu. The Gallup Research Center, the Office of the Research Council, and the John Templeton Foundation provided funding support to Gustavo Carlo.

Associate Professor at the University of Nebraska - Lincoln. Received PhD in Developmental Psychology from Arizona State University. Research interests are the parental, dispositional, and cultural correlates of prosocial and moral development. To whom correspondence should be addressed at Department of Psychology, University of Nebraska - Lincoln, Lincoln, Nebraska, 68588-0308; e-mail: gcarlo1@unl.edu.

Doctoral candidate at the University of Nebraska - Lincoln. She expects to complete her PhD in Developmental Psychology in Spring, 2002. Major research interest is to examine prosocial and moral development in children and adolescents.
} 
prosocial behavior measure is an assessment of prosocial behaviors in specific contexts. These assessments are often behavioral observations of helping opportunities (e.g., picking up dropped items, donating money) designed for specific studies, often experimental studies. Although evidence for the reliability and validity of such measures has been presented, there are reasons to believe that there is limited utility to both assessment approaches.

Global prosocial behavior or social competence measures are limited because prior researchers have shown that there are different types of prosocial behaviors and that each of these types has different personal and situational correlates. Some researchers have presented evidence that there are differences between individuals who help others when they are asked to and those who do so spontaneously (Eisenberg et al., 1981). Other researchers have shown that there are individual differences in children who exhibit prosocial behaviors in high vs. low emotionally evocative situations (Carlo et al., 1991a). Furthermore, some helping behaviors are motivated by internalized norms/principles and sympathy responding and other helping behaviors are motivated by extrinsic motivators (e.g., gaining the approval of others) (Eisenberg and Fabes, 1998). The use of global, rather than situation-specific, assessments of prosocial behaviors has been presented as one possible explanation for prior weak and inconsistent relations between sociocognitive and socioemotional variables and prosocial behaviors (Carlo et al., 1991b; Kurdek, 1978; Underwood and Moore, 1982). Thus, global measures of prosocial behavior might limit investigators' ability to address specific conceptual questions regarding the correlates of prosocial behaviors.

In contrast, situation-specific prosocial behavior measures are useful in addressing specific conceptual questions about the development and correlates of different types of prosocial behaviors. Furthermore, observational and behavioral assessments of these behaviors might be considered more ecologically valid than paperand-pencil measures. However, there are potential limitations to the use of these measures. First, these measures are susceptible to observer and coding biases. Second, some of these measures require individual assessment; thus, these measures might be costly in time and often preclude the assessment of prosocial behaviors in applied settings and in longitudinal studies. And third, evidence of the psychometric qualities of these types of measures is often limited to the evidence presented in the particular study for which it was designed. Researchers have pointed out that standardization of measures is necessary to enable researchers to compare and integrate findings across studies. Furthermore, there is no existing paper-and-pen- cil measure of specific types of prosocial behaviors to use with late adolescents. Given the evidence for changes in prosocial behaviors and theoretically related personal and social contextual variables (e.g., moral reasoning, perspective taking, sympathy, parent and peer relationships) during adolescence (Carlo et al., 1999a; Fabes et al., 1999), an objective measure of prosocial behavior was constructed and designed to assess different types of prosocial behaviors in late adolescents.

\section{Types of Prosocial Behaviors}

Initially, based on prior theory and research, 4 types of prosocial behaviors were identified: altruistic prosocial behaviors, compliant prosocial behaviors, emotional prosocial behaviors, and public prosocial behaviors. Descriptions of each type are presented below.

\section{Altruism}

Altruistic prosocial behaviors were defined as voluntary helping motivated primarily by concern for the needs and welfare of another, often induced by sympathy responding and internalized norms/principles consistent with helping others (Eisenberg and Fabes, 1998). Moreover, because the helper is primarily concerned with the needy others' welfare, these behaviors sometimes incur a cost to the helper. Although scholars have debated whether altruistic behaviors exists (see Batson, 1991), there are at least 3 lines of evidence that support the existence of altruism (Eisenberg et al., 1999). First, researchers have presented evidence of the heritability of sympathy (e.g., Matthews et al., 1981) which is deemed evolutionarily adaptive. Second, there is longitudinal evidence of stability in the tendency to behave in a prosocial manner across childhood and adolescence (Davis and Franzoi, 1994; Eisenberg et al., 1999). And third, researchers have found significant associations between personality variables and prosocial behaviors across different contexts (Carlo et al., 1991a; Staub, 1978).

As mentioned previously, the two primary motives for altruistic actions are sympathy and internalized norms/ principles. Empathy is an emotional reaction that stems from another's emotional state and is congruent with that state (Eisenberg and Fabes, 1998). Theorists have argued that empathy can lead to either sympathy, which is concern or sorrow for another based on the perception and understanding of their emotional state (the focus orientation is on the other), or personal distress, which is an aversive emotional reaction based on the perception and understanding of another's emotional state (the focus ori- 
entation is on the self) (Eisenberg and Fabes, 1998). Researchers have hypothesized that sympathy results in a motivation to relieve the other person's distress, while personal distress results in a motivation to relieve one's own distress (Batson, 1991; Hoffman, 1991). Several investigators have demonstrated that sympathy is associated with altruistic responding while personal distress is associated with egoistic responding (Batson et al., 1986; Carlo et al., 1991a). A related variable associated with sympathy and altruistic responding is perspective taking, or the tendency to take the point of view of another (sometimes referred to as empathic accuracy) (Davis, 1983; Iannotti, 1985; Ickes et al., 1990; Kurdek, 1978; Selman, 1980). Perspective taking has been hypothesized to encourage sympathy and the performance of prosocial behavior, and there is substantial evidence to support these assertions across childhood and adolescence (Iannotti, 1985; Schroeder et al., 1995; Underwood and Moore, 1982).

Another primary motive associated with altruistic responding is internalized norms or principles concerning helping. According to theorists (Blasi, 1980; Colby and Kohlberg, 1987; Rest, 1983), internalized norms and principles are often exhibited at higher levels or stages of moral reasoning when individuals are capable of higher order formal operations thinking, a characteristic of adolescents (Carlo et al., 1992; Fabes et al., 1999). Because these principles are strongly internalized (and often become part of the individual's self concept), individuals with principles concerning helping are likely to engage in behaviors to primarily benefit others in need. Furthermore, individuals who demonstrate high level moral reasoning are likely to engage in behaviors consistent with their reasoning because they have acquired a sense of responsibility to conform to their principles (Kohlberg and Candee, 1984) and are less likely to be influenced by extrinsic motivators (Rholes and Bailey, 1983). Several investigators have demonstrated that high levels of moral reasoning (reasoning that often depicts internalized norms, principles, or empathic-based concerns) are related to prosocial behaviors (Blasi, 1980; Colby and Kohlberg, 1987; Eisenberg et al., 1995). In addition, a number of investigators have shown that altruistic prosocial behaviors are associated with social responsibility (an obligation or duty to act in a manner that benefits society) and ascription of responsibility (a duty or obligation towards the needs and welfare of others) (Batson et al., 1986; Carlo et al., 1991a; Schroeder et al., 1995; Schwartz and Howard, 1984; Staub, 1978). Thus, adolescents who ascribe responsibility to themselves and who believe they have an obligation to act responsibly towards society were expected to be more likely to endorse altruistic prosocial behaviors.

\section{Compliant}

Compliant prosocial behaviors were defined as helping others in response to a verbal or nonverbal request (Eisenberg et al., 1981). Compliant helping is more frequent than spontaneous helping and much of the research on this type of helping has been conducted with children rather than adolescents. Children (especially boys) who comply frequently tend to ask for adult help more often, are unlikely to defend toys, and are less likely to respond positively to peers' prosocial behaviors. (Eisenberg et al., 1981). However, teachers tended to respond positively to girls, rather than boys, who comply with requests for prosocial action. The unique characteristics associated with compliant helping are not confined to the preschool years; elementary school children who frequently engage in compliant prosocial behavior have been found to be relatively nonassertive (Eisenberg and Fabes, 1998). However, additional research is needed on the characteristics of older individuals who engage in high levels of compliant helping. Conceptually, higher levels of compliant helping would be expected to be associated with greater use of approval-oriented modes of moral reasoning and would not be expected to be associated with perspective taking, sympathy, or higher levels of moral reasoning.

\section{Emotional}

Emotional prosocial behaviors were conceptualized as an orientation toward helping others under emotionally evocative circumstances. Some helping situations can be characterized as highly emotionally charged. For example, an adolescent who has hurt his or her arm, is crying and is bleeding, is more emotionally evocative than an adolescent who has hurt his or her arm but shows little or no distress or injury. A number of other factors (e.g., relationship to the needy other, perceived similarity) might influence the level of emotional evocativeness and, in turn, perceived emotional evocativeness might influence the observer's emotional responses. For some individuals, highly emotionally evocative situations are likely to lead to overarousal and personal distress; whereas, for other individuals, the response might be sympathy (Eisenberg and Fabes, 1998; Hoffman, 1982). These emotional responses have been linked to emotion regulation skills and to selfless and egoistic modes of helping (Eisenberg and Fabes, 1998). In general, however, helping in highly emotionally evocative situations would be expected to be strongly associated with sympathy responding and other-oriented personal tendencies (e.g., perspective taking, higher level, empathic modes of moral reasoning) (Bryant, 1982; Carlo et al., 1991a). 


\section{Public}

Prosocial behaviors conducted in front of an audience are likely to be motivated, at least in part, by a desire to gain the approval and respect of others (e.g., parents, peers) and enhance one's self-worth. One common manipulation in research on prosocial behavior is to alter whether others serve as witnesses to the potential prosocial act (e.g. Buhrmester et al., 1992). Researchers have shown that helping conducted in front of others is sometimes associated with self-oriented motives, although researchers have pointed out that social desirability concerns are not necessarily incompatible with prosocial behavior (Schroeder et al., 1995). Furthermore, helping is more likely to occur when one's actions are conducted in front of an audience (but see the research on bystander intervention in emergency situations for exceptions, Schroeder et al., 1995). Because gaining others' approval is often a concern for adolescents, it was hypothesized that public prosocial behaviors would be related positively to approval-oriented modes of moral reasoning and to social desirability (i.e., tendency to present one's self in a positive light). Moreover, public prosocial behaviors were expected to be related negatively (or unrelated) to higher levels of moral reasoning and other-oriented personal tendencies (e.g., sympathy, perspective taking).

\section{Anonymous and Dire}

Based on exploratory factor analyses from 3 pilot studies, the public prosocial behaviors subscale loaded into 2 distinct factors, public and anonymous prosocial behaviors. Anonymous prosocial behaviors were defined as helping performed without knowledge of whom helped. A tendency to perform prosocial acts in front of others was defined as public prosocial behaviors. In addition, the emotional prosocial behaviors subscale loaded into 2 distinct factors, dire and emotional prosocial behaviors. Respondents distinguished between helping in crisis or emergency situations (i.e., dire prosocial behaviors) and situations that contain emotionally evocative cues (i.e., emotional prosocial behaviors). Thus, 6 different types of prosocial behaviors were examined, public, anonymous, dire, emotional, compliant, and altruism. Moreover, although some vocabulary skills are required to read and comprehend items of the PTM, vocabulary skills were not expected to be related strongly to the PTM subscales.

\section{Gender Differences in Prosocial Behaviors}

Eagly and Crowley (1986), in a meta-analytic review of gender differences in helping, showed gender differ- ences in prosocial behavior. Based on social role theory, these authors demonstrated that the relations between gender and helping differed as a function of the type of helping examined. Specifically, helping that was more heroic or more chivalrous was exhibited more often by young men than young women, whereas helping embedded in a relational context was exhibited by young women more than young men. Based on prior studies (e.g., Eagly and Crowley, 1986; Maccoby and Jacklin, 1974), it was hypothesized that late adolescent girls would report higher levels of emotional, altruistic, and compliant prosocial behaviors than late adolescent boys. Furthermore, adolescent boys were expected to report higher levels of public prosocial behaviors than adolescent girls.

\section{STUDY 1}

\section{Method of Study 1}

\section{Participants}

Participants were 249 college students (104 males, 145 females; $M$ age $=19.89$ years, $\mathrm{SD}=2.76$ ) who were enrolled in undergraduate psychology courses at a Midwestern state university. Participants were recruited from undergraduate psychology courses and received extra credit for participation.

\section{Instruments}

Prosocial Tendencies Measure. Items for the Prosocial Tendencies Measure (PTM) were selected from previously developed prosocial disposition and behavior scales (Johnson et al., 1989; Rushton et al., 1981) and from responses to prosocial moral reasoning interviews with college-aged students (Eisenberg et al., 1995). The 23-item version of the PTM was composed of 6 sub-scales: public (4 items, Cronbach's $\alpha=0.78$ ), anonymous (5 items, Cronbach's $\alpha=0.85$ ), dire (3 items, Cronbach's $\alpha=$ 0.63 ), emotional (4 items, Cronbach's $\alpha=0.75$ ), compliant (2 items, Cronbach's $\alpha=0.80$ ), and altruism (5 items, Cronbach's $\alpha=0.74)$. Participants were asked to rate the extent to which statements described themselves on a 5point scale ranging from 1 (does not describe me at all) to 5 (describes me greatly). The final version of the measure is presented in the Appendix.

Prosocial Moral Reasoning. The paper-and-pencil measure of prosocial moral reasoning (PROM-R) was administered (Carlo et al., 1992; Eisenberg et al., 1995). The PROM-R contains 7 stories, each of which contains a conflict between a protagonist's needs and desires and 
those of (an)other(s). The protagonist in each story is the same gender as the participant. The following is a sample story from the PROM-R:

\begin{abstract}
One day Mary was going to a friend's party. On the way, she saw a girl who had fallen down and hurt her leg. The girl asked Mary to go to the girl's house and get her parents so the parents could come and take her to a doctor. But if Mary did run and get the girl's parents, Mary would be late to the party and miss the fun and social activities with her friends.
\end{abstract}

The participant is asked to read each story, and indicate whether the protagonist should (a) help the needy other, (b) not help the needy other, or (c) whether they were unsure what the participant should do. Participants were then asked to rate on a 7-point scale (from 1 (not at all)to7(greatly)) the importance of the 9 reasons why the protagonist should or should not help the needy other in the story.

A representative sample of frequently reported prosocial moral reasoning was selected for each story. Each of the stories included 2 hedonistic items (Level 1 in Eisenberg's model, Eisenberg et al., 1995, which consists of simple hedonistic or direct reciprocity reasoning; e.g., "It depends how much fun Mary expects the party to be, and what sorts of things are happening at the party"), one needs-oriented item (Level 2; e.g., "It depends whether the girl really needs help or not"), two approval-oriented items (Level 3; e.g., "It depends whether Mary's parents and friends will think she did the right or she did the wrong thing"), and one stereotypic item (Level 3; e.g., "It depends if Mary thinks it's the decent thing to do or not"). Each story also contained 2 internalized items, which reflect a higher level of reasoning (Levels 4 and 5), and consists of sympathy, role-taking, positive or negative affect, generalized reciprocity, or internalized value items (e.g., "It depends how Mary would feel about herself if she helped or not"). The 9th reasoning choice was a lie/nonsense item (e.g., "It depends whether Mary believes in people's values of metacognition or not"). The lie items were not used in the present study.

Scores were derived by summing the items across the 7 stories for each of the 5 types of prosocial moral reasoning to obtain a frequency score. The frequency PROM-R scores were transformed to proportion PROM-R scores by dividing each of the scores for the 5 types of moral reasoning by the sum of the frequency PROM-R scores. This gives a score that reflects a participant's preference for a particular reasoning type relative to the other reasoning types. There were 14 hedonistic items (Cronbach's $\alpha$ $=0.85), 7$ needs-oriented items (Cronbach's $\alpha=0.71), 14$ approval items (Cronbach's $\alpha=0.93), 7$ stereotypic items
(Cronbach's $\alpha=0.77$ ), and 14 internalized items (Cronbach's $\alpha=0.87$ ).

Global Prosocial Behavior. The 20-item, self-report measure developed by Rushton et al., (1981) was used to obtain a global index of prosocial behavior responding. Participants were asked to rate the frequency of various behaviors on a 5-point scale ranging from 1 (never) to 5 (very often) (e.g., "I have delayed an elevator and held the door open for a stranger"; Cronbach's $\alpha=0.83$ ).

Empathy. Three subscales of a multidimensional measure of empathy (Davis, 1983) were used to examine perspective taking (e.g., "I try to look at everybody's side of a disagreement before I make a decision"; 7 items, Cronbach's $\alpha=0.82$ ), empathic concern, hereafter referred to as sympathy (e.g., "I am often quite touched by things that I see happen"; 7 items, Cronbach's $\alpha=0.75$ ) and personal distress (e.g., "In emergency situations, I feel anxious and ill-at-ease"; 7 items, Cronbach's $\alpha=$ 0.78). Participants were asked to rate how well each item describes them on a 5-point scale ranging from 1 (does not describe me well) to 5 (describes me very well).

Social Desirability. A shortened, 25-item version of Crowne and Marlowe's scale was administered to assess individuals' tendency to present themselves in a positive manner to others (Crowne and Marlowe, 1964). Participants were asked to rate whether each item was true or false as it pertained to themselves (e.g., "There have been occasions when I felt like smashing things," Cronbach's $\alpha=0.71$ ).

Ascription of Responsibility. A 29-item measure developed by Schwartz (1968) was used to assess people's tendencies to ascribe responsibility for events to themselves. Participants were asked to rate their level of agreement with each item on a 5-point scale ranging from 1 (strongly agree) to 5 (strongly disagree) (e.g., "I would feel less bothered about leaving litter in a dirty park than a clean one"; Cronbach's $\alpha=0.81$ ).

Social Responsibility. An 8-item measure developed by Berkowitz and Lutterman (1968) was used to assess the degree to which individuals view themselves as having a duties or obligations toward their society. Participants were asked to rate their level of agreement with each item on a 5-point scale ranging from 1 (strongly disagree) to 5 (strongly agree) (e.g., "Every person should give some of his time for the good of his town or country"; Cronbach's $\alpha=0.69$ ).

Vocabulary Skills. A shortened, 40-item version of the Quick Word Test (Borgatta and Corsini, 1960) was used to assess vocabulary skills. A target word is presented, along with 4 choices from which the participant has to choose the target word's synonym. Scores were based 
Table I. Means, Standard Deviations, and Ranges of the Prosocial Tendencies Measure for the Total Sample and Separately for Males and Females in Study 1

\begin{tabular}{llllc}
\hline & $N$ & $M$ & SD & Range \\
\hline Public (Total) & 248 & 2.06 & 0.75 & $1-4.75$ \\
$\quad$ Males & 103 & 2.31 & 0.76 & $1-4.75$ \\
Females & 145 & 1.88 & 0.69 & $1-4$ \\
Anonymous (Total) & 248 & 2.77 & 0.94 & $1-5$ \\
Males & 103 & 2.53 & 0.86 & $1-4.8$ \\
Females & 145 & 2.94 & 0.96 & $1-5$ \\
Dire (Total) & 248 & 3.53 & 0.77 & $1-5$ \\
Males & 103 & 3.58 & 0.71 & $1.33-5$ \\
Females & 145 & 3.50 & 0.81 & $1-5$ \\
Emotional (Total) & 248 & 3.70 & 0.77 & $1.5-5$ \\
Males & 103 & 3.56 & 0.82 & $1.5-5$ \\
Females & 145 & 3.80 & 0.71 & $1.5-5$ \\
Compliant (Total) & 248 & 3.82 & 0.83 & $1.5-5$ \\
Males & 103 & 3.65 & 0.84 & $1.5-5$ \\
Females & 145 & 3.94 & 0.80 & $2-5$ \\
Altruism (Total) & 248 & 4.18 & 0.70 & $1.4-5$ \\
Males & 104 & 3.99 & 0.70 & $2-5$ \\
Females & 145 & 4.32 & 0.67 & $1.4-5$ \\
\hline
\end{tabular}

upon the total number of correct responses (e.g., "tuber: bulb, horn, tape, or rash"; Cronbach's $\alpha=0.68$ ). The measure has been shown to be related strongly to measures of intelligence (e.g., Borgatta and Corsini, 1960).

\section{Procedure}

Participants, in groups of approximately 30 students, participated in an experimental session which lasted approximately $1 \mathrm{~h}$. All sessions were held in university classrooms. Participants were informed that they were participating in a study to assess the validity of a psychological instrument, assured of anonymity and confidentiality, and their consent to participate was obtained. All measures were administered in a randomized order. Participants were then debriefed and thanked.

\section{Results of Study 1}

Descriptive Statistics, Gender Differences, and Interrelations Among PTM Subscales

The means, standard deviations, and ranges for the subscales of the PTM are presented in Table I. Adolescents reported altruistic prosocial behaviors the most, fol- lowed by compliant, emotional, dire, anonymous, and public prosocial behaviors, respectively. A multivariate analysis of variance (MANOVA) was conducted to examine gender differences in the types of prosocial behaviors (see Table I for means separately by gender). There was a significant multivariate main effect of gender on prosocial behaviors, $F(1,239)=6.67, p<0.001$. Univariate follow-up tests indicated that adolescent boys scored higher on public prosocial behaviors than did adolescent girls, $F(1,246)=19.44, p<0.001$. In contrast, adolescent girls scored higher than adolescent boys on altruism, $F(1$, $246)=12.89, p<0.001$, anonymous prosocial behaviors, $F(1,246)=13.35, p<0.001$, compliant prosocial behaviors, $F(1,246)=6.88, p<0.01$, and emotional pro-social behaviors, $F(1,246)=6.50, p<0.01$. There were no gender differences in dire prosocial behaviors $(p>0.10)$.

Zero-order correlations were computed to examine the interrelations among the PTM subscales (see Table II). In general, the subscales of the PTM were positively and modestly interrelated with some exceptions:

1. The public subscale was significantly negatively correlated with the anonymous, compliant, and altruism subscales;

2. The dire subscale was related strongly to the emotional subscale;

3. And, the public subscale was not related significantly with the dire or emotional subscales and the altruism subscale was not related significantly with the anonymous or dire subscales.

\section{Factor Structure of the PTM}

To further examine the relations among the items of the PTM, a varimax rotated principal components exploratory factor analysis was conducted. An exploratory, rather than confirmatory, factor analysis was conducted because this was the first study using the PTM. As shown in Table III, 6 distinct factors emerged accounting for $63.38 \%$ of the systematic variance in responding. For interpretation purposes, items with a factor loading of at least 0.40 were considered to load on that factor (with the exception of 1 item from the altruism subscale that had a

Table II. Interrelations Among the Prosocial Tendencies Measure Subscales in Study 1

\begin{tabular}{|c|c|c|c|c|c|c|}
\hline & Public & Anorymous & Dire & Emotional & Compliant & Altruism \\
\hline Public & - & & & & & \\
\hline Anonymous & $-0.19^{+*}$ & & & & & \\
\hline Dire & 0.02 & $0.29 * * *$ & & & & \\
\hline Emotional & -0.12 & $0.29 * * *$ & $0.50^{+* 4}$ & & & \\
\hline Compliant & $-0.23^{* * 4}$ & $0.25^{+* 4}$ & $0.32^{+* 4 *}$ & $0.36^{*+*}$ & & \\
\hline Altnuism & $-0.64^{* * *}$ & 0.12 & 0.03 & $0.20^{* *}$ & $0.22^{* * *}$ & - \\
\hline
\end{tabular}


Table II. Vanimax Rotated Factor Loadings for the Prosocial Tendencies Measure Items

\begin{tabular}{lrrrrrr}
\hline \multicolumn{1}{c}{ Items } & Factor 1 & Factor 2 & Factor 3 & Factor 4 & Factor 5 & Factor 6 \\
\hline Anonymous 1 & 0.74 & -0.08 & 0.08 & 0.08 & 0.01 & -0.03 \\
Anonymous 2 & 0.82 & -0.11 & -0.01 & 0.17 & -0.01 & 0.13 \\
Anonymous 3 & 0.77 & -0.02 & 0.03 & 0.12 & 0.02 & 0.25 \\
Anonymous 4 & 0.78 & -0.01 & 0.06 & -0.10 & 0.18 & 0.06 \\
Anonymous 5 & 0.76 & -0.13 & -0.01 & 0.17 & 0.16 & -0.04 \\
Public 1 & -0.16 & 0.81 & -0.07 & 0.07 & -0.04 & 0.01 \\
Public 2 & -0.08 & 0.84 & -0.07 & 0.15 & -0.08 & -0.05 \\
Public 3 & 0.01 & 0.64 & -0.32 & -0.21 & -0.06 & 0.07 \\
Public 4 & -0.15 & 0.49 & -0.53 & -0.09 & -0.04 & 0.07 \\
Altruism 1 & 0.11 & -0.54 & 0.48 & 0.19 & 0.11 & -0.11 \\
Altruism 2 & -0.12 & -0.13 & 0.59 & 0.11 & 0.18 & -0.06 \\
Altruism 3 & 0.12 & -0.19 & 0.77 & 0.04 & -0.09 & -0.04 \\
Altruism 4 & -0.03 & -0.61 & 0.39 & 0.15 & 0.01 & 0.04 \\
Altruism 5 & 0.06 & -0.16 & 0.76 & -0.10 & 0.04 & 0.17 \\
Emotional 1 & 0.07 & 0.15 & 0.21 & 0.62 & 0.36 & 0.01 \\
Emotional 2 & 0.12 & -0.09 & 0.20 & 0.65 & 0.11 & 0.33 \\
Emotional 3 & 0.08 & -0.14 & -0.11 & 0.69 & 0.05 & 0.34 \\
Emotional 4 & 0.19 & -0.04 & -0.01 & 0.79 & 0.04 & 0.10 \\
Compliant 1 & 0.14 & -0.12 & 0.10 & 0.09 & 0.82 & 0.17 \\
Compliant 2 & 0.15 & -0.09 & 0.04 & 0.18 & 0.85 & 0.07 \\
Dire 1 & 0.01 & -0.04 & -0.02 & 0.15 & 0.43 & 0.64 \\
Dire 2 & 0.01 & 0.07 & -0.02 & 0.32 & 0.04 & 0.68 \\
Dire 3 & 0.34 & 0.04 & 0.02 & 0.13 & 0.04 & 0.71 \\
\hline
\end{tabular}

Note. Eigenvalues for each factor were $>1.0$. Factor 1 accounted for $14.45 \%$ of the variance, Factor 2 accounted for $12.45 \%$ of the variance, Factor 3 accounted for $10.49 \%$ of the variance, Factor 4 accounted for $10.20 \%$ of the variance, Factor 5 accounted for $8.06 \%$ of the variance, and Factor 6 accounted for $7.73 \%$ of the variance.

loading of 0.39). In general, the factors that emerged corresponded conceptually to the subscales of the PTM.

All 5 of the items making up the anonymous prosocial behaviors subscale loaded positively on Factor 1. All 4 of the public prosocial behaviors items loaded positively on Factor 2 (2 altruism items loaded negatively on this factor). The 5 items from the altruistic prosocial behaviors subscale loaded positively on Factor 3 (1 item from the public subscale loaded negatively on Factor 3). The 4 items from the emotional prosocial behaviors subscale loaded positively on Factor 4 . The 2 items from the compliant prosocial behaviors subscale loaded positively on Factor 5 (although 1 item from the dire subscale also loaded positively on Factor 5). The 3 items from the dire prosocial behaviors subscale loaded on Factor 6.

To further examine the internal consistency of the subscales of the PTM, the corrected item-total correlations for each subscale were examined. These correlations ranged from 0.53 to 0.64 for the public subscale, 0.63 to 0.74 for the anonymous subscale, 0.41 to 0.47 for the dire scale, 0.46 to 0.59 for the emotional subscale, 0.42 to 0.57 for the altruism subscale, and 0.67 for the 2 items of the compliant subscale. Thus, the range of the magnitude of these coefficients was moderate as expected.

\section{Relations of the PTM to the Other Theoretically Related Variables}

Descriptive statistics for the cognitive, emotive, trait value, and social behavior measures are presented in Table IV. To examine the relations of the PTM with other theoretically related constructs, correlational analyses were conducted (see Table V). Because of the number of analyses, only correlation coefficients greater than 0.20 and significant at the $p<0.01$ level were interpreted to reduce family-wise experiment error rates.

Relations with Cognitive Variables. Altruistic prosocial behaviors were related positively to perspective taking, and to stereotypic and internalized prosocial moral reasoning (see Table V). Furthermore, altruistic prosocial behaviors were related negatively to hedonistic and approval-oriented prosocial moral reasoning. Compliant prosocial behaviors were related positively to perspective taking and internalized prosocial moral reasoning. Emotional prosocial behaviors were related positively to per- 
Table IV. Descriptive Statistics for the Cognitive, Emotive, Trait Value, and Social Behavior Measures in Study 1

\begin{tabular}{lrrc}
\hline \multicolumn{1}{c}{ Variable } & $M$ & SD & Range of scores \\
\hline Perspective taking & 24.56 & 5.05 & $9-35$ \\
Sympathy & 27.84 & 4.12 & $15-35$ \\
Personal distress & 17.61 & 4.70 & $7-30$ \\
Global prosocial behavior & 54.91 & 10.71 & $20-90$ \\
Social desirability & 40.59 & 2.45 & $32-46$ \\
Approval-oriented reasoning & 0.16 & 0.05 & $0.06-0.31$ \\
Hedonistic reasoning & 0.23 & 0.04 & $0.13-0.33$ \\
Needs-oriented reasoning & 0.14 & 0.03 & $0.06-0.27$ \\
Stereotyped reasoning & 0.14 & 0.02 & $0.06-0.22$ \\
Intemalized reasoning & 0.32 & 0.05 & $0.20-0.47$ \\
Vocabulary skills & 15.21 & 4.89 & $0-29$ \\
Ascription of responsibility & 98.32 & 12.01 & $59-132$ \\
Social responsibility & 31.82 & 4.60 & $15-40$ \\
\hline
\end{tabular}

spective taking, and to stereotypic and internalized prosocial moral reasoning, and related negatively to hedonistic prosocial moral reasoning. Dire and anonymous prosocial behaviors were related positively to perspective taking. In contrast, public prosocial behaviors were related negatively to perspective taking and internalized prosocial moral reasoning, and positively related to hedonistic and approval-oriented prosocial moral reasoning. Moreover, as expected, the PTM was not correlated significantly to vocabulary skills ( $r$ s ranged from -0.07 to 0.10 ).

Relations with Emotive Variables. As expected, sympathy was positively associated with anonymous, dire, emotional, compliant, and altruistic prosocial behaviors (see Table V). In contrast, there was a significant negative correlation between sympathy and public prosocial be- haviors. There were no significant relations between personal distress and the PTM.

Relations with Trait-Value Variables. In general, the PTM subscales were associated positively with ascription of responsibility (see Table V). In contrast, public prosocial behaviors were related negatively to ascription of responsibility. There was no significant relation between dire prosocial behaviors and ascription of responsibility. Social responsibility was related positively to compliant, emotional, dire, and anonymous prosocial behaviors, and unrelated to public or altruistic prosocial behaviors. As expected, social desirability was not correlated significantly with the PTM subscales ( $r$ s ranged from -0.04 to 0.19 ).

Relations with Global Prosocial Behavior. The global prosocial behavior scale was significantly positively related to anonymous, dire, and compliant prosocial behaviors, and not related significantly to altruistic, emotional, or public prosocial behaviors (see Table V).

Relations with an Overall Composite of the PTM. To assess the relative utility of the individual PTM subscales as compared to a composite prosocial behaviors measure, a PTM composite score was computed by summing and averaging the 23 items of the PTM $(M=3.33, \mathrm{SD}=$ 0.53 , Cronbach's $\alpha=0.73$ ). The correlations of the PTM composite to gender and the cognitive, emotive, trait-value, and global prosocial behavior variables were computed. The PTM total score was significantly correlated with perspective taking $(r=0.19, p<0.01)$, stereotypic reasoning $(r=0.20, p<0.01)$, sympathy $(r=0.31, p<$ $0.001)$, ascription of responsibility $(r=0.45, p<0.001)$,

Table V. Correlations Between the Prosocial Tendencies Measure and Cognitive, Emotive, Trait Value, and Global Prosocial Behavior Variables

\begin{tabular}{|c|c|c|c|c|c|c|}
\hline Vaniable & Public & Anonymous & Dire & Emotional & Compliant & Altruism \\
\hline \multicolumn{7}{|l|}{ Cognitive } \\
\hline Perspective taking & $-0.25 * * *$ & $0.24 * *+$ & $0.23+* *$ & $0.26 *+*$ & $0.28^{* * *}$ & $0.28 * 4 *$ \\
\hline Hedonistic reasoning & $0.22 * * *$ & -0.12 & -0.18 & $-0.28^{*+*}$ & -0.12 & $-0.35^{*+*}$ \\
\hline Needs-oriented reasoning & $-0.20^{*+*}$ & 0.06 & -0.06 & -0.03 & 0.04 & 0.14 \\
\hline Approval-oriented reasoning & $0.22 * * *$ & -0.13 & -0.06 & -0.13 & -0.17 & $-0.32^{* 4 *}$ \\
\hline Stereotypic reasoning & -0.11 & 0.14 & 0.14 & $0.22^{*+*}$ & 0.09 & $0.21^{* * *}$ \\
\hline Intemalized reasoning & $-0.24^{* * *}$ & 0.14 & 0.17 & $0.28^{*+*}$ & $0.21^{* * *}$ & $0.45^{*+*}$ \\
\hline \multicolumn{7}{|l|}{ Emotive } \\
\hline Sympathy & $-0.23 * * *$ & $0.30 * *+$ & $0.30^{* * *}$ & $0.47 * * *$ & $0.38 * * *$ & $0.40^{* *+*}$ \\
\hline Personal distress & 0.01 & 0.02 & -0.14 & -0.03 & -0.08 & -0.06 \\
\hline \multicolumn{7}{|l|}{ Trait value } \\
\hline Ascription of responsibility & $-0.27^{*+*}$ & $0.29 * * *$ & 0.18 & $0.33^{* * *}$ & $0.30^{* * *}$ & $0.44^{* * *}$ \\
\hline Social responsibility & -0.05 & $0.28^{* * *}$ & $0.23^{* * *}$ & $0.25^{* * *}$ & $0.28^{* * * *}$ & 0.15 \\
\hline Global prosocial behavior & 0.06 & $0.24^{* * *}$ & $0.32^{* * *}$ & $0.20^{* * *}$ & $0.24^{* * * *}$ & -0.01 \\
\hline
\end{tabular}

Note. To reduce family wise experimenter enror, only coefficients of 0.20 and greater and with probability levels $<0.01$ were interpreted

${ }^{* * *} p<0.001$. 
social responsibility $(r=0.22, p<0.001)$, global prosocial behavior $(r=0.30, p<0.001)$, and hedonistic reasoning $(r$ $=-0.14, p<0.05)$. There were no significant correlations between the PTM composite and approval oriented-reasoning, needs-oriented reasoning, personal distress, social desirability, gender or vocabulary skills (all $p \mathrm{~s} \geq 0.10$ ).

\section{Discussion of Study 1}

\section{Evidence of Different Type of Prosocial Behaviors}

Consistent with prior theorists (e.g., Staub, 1978), the results of Study 1 supported the notion that prosocial behavior is better conceptualized as a set of distinct, yet interrelated, dimensions rather than as a global construct in late adolescence. For example, as expected, adolescents who reported more helping in public contexts were more likely to be concerned with their own needs, were more concerned with gaining others' approval, were less sensitive to others' needs, engaged in less sophisticated forms of reasoning and perspective taking, and were more likely to ascribe responsibility to others. In contrast, adolescents who reported more helping across the 6 different types of the PTM composite were (a) more likely to take the perspective of others, used stereotypic prosocial moral reasoning, reported more sympathy, ascribed responsibility to themselves, reported more social responsibility, and were more likely to help across different situations (i.e., global index of helping), and (b) tended to not use hedonistic prosocial moral reasoning. Thus, the pattern of relations for those adolescents who reported more prosocial behaviors in public contexts was different than for those adolescents who reported more prosocial behaviors across the 6 types.

Furthermore, there were no gender differences using the PTM composite whereas there were several gender differences in the individual subscales of the PTM. Taken together with the results from the factor analysis, internal consistency tests, and the overall weak magnitude of effects in the relations between the PTM composite and the other theoretically relevant constructs, the present findings suggest that adolescents do differentiate among different types of prosocial behaviors. Thus, the structure of prosocial behaviors is differentiated during this age period.

As mentioned earlier, researchers interested in the characteristics of individuals who engage frequently in compliant helping behaviors have focused mostly on children rather than adolescents. In this study, adolescents who reported high levels of compliance preferred empathic, internalized moral reasoning, had perspective tak- ing tendencies, reported more sympathy, were more likely to attribute responsibility to themselves and viewed themselves as more socially responsible. These findings are consistent with expectations that individuals are more likely to comply with other's helping requests when they understand the other's situation, are sympathetic to their needs, feel socially responsible to help others, and ascribe responsibility to themselves.

The characteristics of anonymous helpers and of adolescents who described themselves as helpers under dire circumstances were similar except anonymous helpers were more likely to ascribe responsibility to themselves. However, both of these latter individuals viewed themselves as more sympathetic and socially responsible and reported high levels of perspective taking.

As expected, altruistically inclined adolescents reported higher levels of internalized, principled prosocial moral reasoning, perspective taking, sympathy, ascription of responsibility, and lower levels of hedonistic and approval-oriented prosocial moral reasoning. These results are consistent with findings from experimental studies that suggest a link between empathy and altruism (Batson, 1998). Furthermore, the findings support prior findings that altruists tend to use relatively sophisticated cognitive skills (e.g., higher level moral reasoning and perspective taking; Eisenberg and Fabes, 1998). Adolescents who viewed themselves as more likely to help in emotionally-evocative contexts were similar to those adolescents who reported high levels of altruism, except that the former individuals reported more social responsibility and used stereotyped moral reasoning (e.g., concepts about kindness and generosity). Perhaps their relatively high level of emotional sensitivity facilitates a self-concept that includes a notion of the self as kind, generous, and socially responsible. Future researchers could examine this possibility by examining the direct link between adolescents' self-concept and prosocial behaviors in emotional contexts.

\section{Interrelations Among Prosocial Behaviors}

In late adolescence, public and altruistic prosocial behaviors were strongly negatively interrelated, and the dire and emotional prosocial behaviors were strongly positively interrelated. While one could argue that these related subscales of the PTM should be combined, this might be a premature conclusion. This is because distinctions between public prosocial behaviors and altruistic prosocial behaviors and between dire prosocial behaviors and emotional prosocial behaviors might be conceptually important. For example, in many instances, highly 
emotionally evocative cues will be present in dire or extreme circumstances. However, not all highly emotionally charged circumstances are necessarily characterized by direness. For instance, an adolescent who has fallen and scraped his or her leg might be likely to display high levels of pain and distress but the circumstance might not be deemed as dire or as an emergency by an adult observer. Conversely, an adult might deem the fall to be an emergency even when the adolescent does not display high level of distress or pain.

Furthermore, those adolescents who tend to be more prosocial in public settings might be motivated by different or additional concerns than adolescents who engage frequently in altruistic prosocial behaviors. Moreover, tendencies toward a specific set of behaviors do not preclude tendencies toward another set of specific behaviors. Gaining others' approval and enhancing one's self-concept might be associated with more public prosocial behaviors; in contrast, individuals who engage in more altruistic prosocial behaviors might be influenced by motives such as strongly internalized norms or sympathy. However, these motives do not necessarily function independently. There might be circumstances when all these motives are relevant (or conflict with each other) in a situation (e.g., an altruistically motivated act performed in front of others). Furthermore, adolescents might have tendencies to perform helping behaviors in front of others (i.e., public prosocial behaviors) as well as helping behaviors with a relatively high cost to the self (i.e., altruistic prosocial behaviors). In light of the fact that the dire, emotional, public, and altruism sub-scales loaded into their own distinct factors (there was some minimal overlap), collapsing these subscales might inhibit researchers' ability to discern potentially important individual and group differences in these behaviors and potentially important theoretical distinctions would be overlooked.

\section{Gender Differences in Prosocial Behaviors}

Several interesting gender differences emerged from the results of Study 1. Adolescent girls scored higher than adolescent boys on altruistic, anonymous, compliant, and emotional types of prosocial behaviors. These results build upon prior research on gender differences in prosocial behavior in adolescence (Fabes et al., 1999). The finding that adolescent girls reported more of these types of prosocial behaviors than adolescent boys was consistent with prior findings (see Eagly and Crowley, 1986). A number of scholars have noted that girls exhibit more sympathy (especially using self-report measures, see Eisenberg and Miller, 1987) and some higher level forms of internalized prosocial moral reasoning (Eisenberg et al., 1995). Furthermore, other researchers have shown that adolescent boys are more concerned with gaining others' approval than adolescent girls (Carlo et al., 1999b). Taken together, these findings suggest that adolescent girls might be most likely to engage in prosocial behaviors when internalized, empathic motives are relevant and when there are fewer concerns with gaining others' approval such as altruistic, anonymous, and emotional pro-social opportunities.

There were other interesting gender differences in reported prosocial behaviors. The fact that adolescent girls reported more compliant prosocial behaviors than adolescent boys was consistent with strong gender role stereotypes about such behaviors and with existing social pressures for girls to comply with asked for assistance (Maccoby and Jacklin, 1974). However, Eagly and Crowley (1986) did not find overall gender differences in compliant prosocial behaviors. Therefore, more research is needed to discern the apparent inconsistencies between the present and prior findings. In contrast to these gender differences, adolescent boys reported a greater tendency to engage in public forms of prosocial behaviors than did adolescent girls. This finding was consistent with results of prior studies examing actual performance of prosocial behavior that showed a greater tendency for men to help others when an audience is present (Eagly and Crowley, 1986).

Interestingly, adolescent girls reported more emotional prosocial behaviors than adolescent boys; however, there were no significant gender differences in dire pro-social behaviors. Perhaps dire or emergency prosocial behaviors are exhibited in strong environments that overwhelm personal tendencies related to gender. Thus, although theorists have advocated the idea that men help more than women in situations congruent with a heroic or chivalrous role (Eagly and Crowley, 1986), it is possible that women feel equally able to help in crisis situations, especially when they are embedded in a close relational context. Conversely, women report more emotional sensitivity than men, which might lead to more helping in dire circumstances (because many of these circumstances would be emotionally evocative). However, emergency circumstances might be more likely to induce helping from men, especially when the helping requires heroic actions. Thus, it is possible that dire circumstances have a combination of characteristics that evoke responses from individuals that are not gender based.

In summary, evidence was presented on the utility of the PTM as a measure of prosocial behaviors to use with late adolescents. Furthermore, the findings provided evi- 
dence that the structure of prosocial behaviors and pattern of relations to other theoretically relevant variables in late adolescence is differentiated.

\section{STUDY 2}

Although the first study yielded much information about the psychometric properties of the PTM and the correlates of prosocial behaviors, an additional study was conducted to examine the test-retest reliability of the PTM and to examine the relations of the PTM to other measures of prosocial behaviors. Two additional paperand-pencil measures of prosocial behavior were selected for a follow-up study.

\section{Method of Study 2}

\section{Participants}

Participants were 40 college students (12 males, 28 females; $M$ age $=22.88$ years, $\mathrm{SD}=4.47$ ), who were enrolled in undergraduate psychology courses at a Midwestern state university. Participants were recruited from undergraduate psychology courses and received extra credit for participation.

\section{Instruments}

Prosocial Tendencies Measure. As in Study 1, the 23-item version of the PTM consisting of 6 subscales: public (4 items, Cronbach's $\alpha=0.80$ ), anonymous (5 items, Cronbach's $\alpha=0.88$ ), dire (3 items, Cronbach's $\alpha$ $=0.54$ ), emotional (4 items, Cronbach's $\alpha=0.77)$, compliant ( 2 items, Cronbach's $\alpha=0.87$ ), and altruism (5 items, Cronbach's $\alpha=0.62$ ) was used.

Helping Behavior Measure. The prosocial behavior subscale from the Primary Prevention Awareness, Attitudes and Usage Scale (PPAAUS; Swisher et al., 1985) was used to assess helping. This is a 6-item scale that includes items tapping into volunteering in a charitable organization, helping a friend with a problem, raising or donating money, sharing in household tasks, and doing favors or lending money to others. Responses could range from 1 (never happened) to 6 (happens almost every day). Cronbach's alpha coefficient was 0.65 .

Altruistic Behavior Measures. The altruism scale developed by Johnson et al. (1989) was included. The items from the scale were classified post hoc into 5 categories of prosocial behavior by a group of psychologists on the basis of the nature of sacrifice (Johnson et al., 1989). The
5 categories were time, time plus effort or pain, money or goods, risk of harm, and loss of status. The 29 items from the time and time plus effort/pain categories were used. Responses could range from 1 (never) to 5 (very often). Cronbach's alpha coefficients were 0.68 for time/effort (11 items) and 0.84 for time (18 items).

\section{Procedure}

The students (in groups of approximately 15) participated in 2 experimental sessions. Each session lasted 1520 min and was conducted 2 weeks apart. In session 1, the students were administered a demographic information sheet and the PTM. In session 2, the students were administered the PTM, the altruism subscales, and the helping measure.

\section{Results of Study 2}

Means (and standard deviations) for the scales were as follows: 2.03 (0.65) for public PTM scale, $2.70(0.95)$ for anonymous PTM scale, 3.53 (0.70) for dire PTM scale, 3.66 (0.72) for emotional PTM scale, 4.26 (0.54) for altruism PTM scale, 4.06 (0.81) for compliant PTM scale, 2.97 (0.56) for time altruism scale, 2.24 (0.51) for time/effort altruism scale, and 4.10 (0.61) for helping behavior measure.

\section{Test-Retest Reliability of the PTM}

Two-week, test-retest reliability correlation coefficients were $0.61,0.75,0.72,0.80,0.73$, and 0.60 (all $p$ s $<0.001$ ) for public, anonymous, dire, emotional, compliant, and altruism, respectively.

\section{Relations Between the PTM and Measures of Prosocial Behavior}

Zero-order correlations were computed to examine the relations between the public, anonymous, dire, emotional, compliant, and altruism subscales of the PTM and the time altruism, time/effort altruism, and helping measures. The compliant PTM scale was significantly positively correlated with the helping measure, $r(36)=0.45$, $p<0.005$, and the time altruism scale, $r(36)=0.58, p$ $<0.001$. Furthermore, the dire PTM scale was related significantly to both the time and time/effort altruism scales, $r \mathrm{~s}(36)=0.42$ and $0.44, p \mathrm{~s}<0.01$, respectively. There were no other significant relations. 


\section{Discussion of Study 2}

The findings from Study 2 yielded evidence for the short-term temporal stability of the 6 PTM subscales and showed further evidence of convergent validity with other measures of prosocial behaviors. The compliant subscale of the PTM was associated with both the helping and time altruism (but not the time/effort altruism) scales. These findings suggest that the compliant subscale of the PTM assesses compliant forms of behaviors but not other forms of prosocial behaviors. A review of the items from the helping measure reveals that many of the items tap into asked for helping such as doing favors for friends or lending money to a friend. Furthermore, the time and time/effort altruism scales appeared to tap into both compliant and dire forms of prosocial behaviors rather than emotional, anonymous, public, and altruism (as reflected in the PTM). The importance of extensive examination of the construct validity of prosocial behavior scales is exemplified by these findings.

\section{GENERAL DISCUSSION}

In general, the studies provided evidence of individual differences in prosocial behaviors in late adolescents. For example, adolescents who reported relatively high levels of prosocial behaviors in emotional contexts, when asked to help, or when there is a cost to themselves tended to be more responsible, were more sympathetic, were good at perspective taking, and demonstrated relatively high levels of prosocial moral reasoning. In contrast, adolescents who reported high levels of prosocial behaviors in front of others (i.e., public prosocial behaviors) demonstrated more hedonistic and approval-oriented modes of prosocial moral reasoning (and less internalized prosocial moral reasoning), were less sympathetic towards others, were less likely to ascribe responsibility to themselves, and reported lower perspective taking tendencies. The unique pattern of relations among individuals with different prosocial behaviors suggests that the structure of prosocial behaviors is multidimensional in late adolescence. Future research on the personal and social contextual variables that contribute to individual differences in prosocial behaviors is needed.

The studies also demonstrated adequate internal consistency, temporal stability, construct, discriminant, convergent, and predictive validity of the PTM to use with late adolescents. The internal consistency coefficients, test-retest reliabilities, inter-item total correlations, and the exploratory factor analysis all showed evidence that the PTM is reliable and internally consistent. In general, the correlations between the 6 PTM subscales and other variables were consistent with theory and with prior research. Perhaps more importantly, the use of a multidimensional measure led to a pattern of relations that illuminated the unique individual characteristics associated with different prosocial behaviors. This unique pattern of relations between the PTM subscale and its correlates suggests that the PTM is not likely to reflect more global, theoretically related constructs such as agreeableness. The PTM was designed to tap into some of the common types of prosocial behaviors but other measures might be more useful for assessing other types of prosocial behaviors. Nonetheless, the present findings provide promising evidence for the utility of the PTM to use with late adolescents in future studies. Research is now underway to examine the psychometric properties of the PTM for use with younger adolescents.

\section{APPENDIX}

Below are a number of statements that may or may not describe you. Please indicate HOW MUCH EACH STATEMENT DESCRIBES YOU by using the following scale:

1 (Does not describe me at all),

2 (Describes me a little),

3 (Somewhat Describes me),

4 (Describes me well), and

5 (Describes me greatly)

1. I can help others best when people are watching me.

2. It is most fulfilling to me when I can comfort some one who is very distressed.

3. When other people are around, it is easier for me to help needy others.

4. I think that one of the best things about helping others is that it makes me look good.

5. I get the most out of helping others when it is done in front of others.

6. I tend to help people who are in a real crisis or need.

7. When people ask me to help them, I don't hesitate.

8. I prefer to donate money anonymously.

9. I tend to help people who hurt themselves badly.

10. I believe that donating goods or money works best when it is tax-deductible.

11. I tend to help needy others most when they do not know who helped them.

12. I tend to help others particularly when they are emotionally distressed. 
13. Helping others when I am in the spotlight is when I work best.

14. It is easy for me to help others when they are in a dire situation.

15. Most of the time, I help others when they do not know who helped them.

16. I believe I should receive more recognition for the time and energy I spend on charity work.

17. I respond to helping others best when the situation is highly emotional.

18. I never hesitate to help others when they ask for it.

19. I think that helping others without them knowing is the best type of situation.

20. One of the best things about doing charity work is that it looks good on my resume.

21. Emotional situations make me want to help needy others.

22. I often make anonymous donations because they make me feel good.

23. I feel that if I help someone, they should help me in the future.

\section{REFERENCES}

Bandura, A. (1986). Social Foundations of Thought and Action: A Social Cognitive Theory. Prentice-Hall, Englewood Cliffs, NJ.

Batson, C. D. (1998). Altruism and prosocial behavior. In Gilbert, D. T., Fiske, S. T., and Lindzey, G. (eds.), The Handbook of Social Psychology (4th edn., Vol. 2). McGraw-Hill, Boston, MA, pp. 282-316.

Batson, C. D., Bolen, M. H., Cross, J. A., and NeuringerBenefiel, H. E. (1986). Where is the altruism in the altruistic personality? J. Pers. Soc. Psychol. 50: 212220.

Berkowitz, L., and Lutterman, K. G. (1968). The traditional socially responsible personality. Public Opinion Q. 32: $169-185$.

Blasi, A. (1980). Bridging moral cognition and moral action: A critical review of the literature. Psychol. Bull. 88: $1-45$

Borgatta, E. P., and Corsini, R. J. (1960). The Quick Word Test (QWT). J. Educ. Res. 54: 15-20.

Bryant, B. (1982). An index of empathy for children and adolescents. Child Dev. 53: 413-425.

Buhrmester, D., Goldfarb, J., and Cantrell, D. (1992). Selfpresentation when sharing with friends and nonfriends. J. Early Adolesc. 12: 61-79.
Carlo, G., Eisenberg, N., and Knight, G. P. (1992). An objective measure of adolescents' prosocial moral reasoning. J. Res. Adolesc. 2: 331-349.

Carlo, G., Eisenberg, N., Troyer, D., Switzer, G., and Speer, A. L. (1991a). The altruistic personality: In what contexts is it apparent? J. Pers. Soc. Psychol. 61: 450458.

Carlo, G., Fabes, R. A., Laible, D., and Kupanoff, K. (1999a). Early adolescence and prosocial/moral behavior II: The role of social and contextual influences. J. Early Adolesc. 19: 133-147.

Carlo, G., Knight, G. P., Eisenberg, N., and Rotenberg, K. J. (1991b). Cognitive processes and prosocial behaviors among children: The role of affective attributions and reconciliations. Dev. Psychol. 27: 456-461.

Carlo, G., Roesch, S. C., and Koller, S. H. (1999b). Similarities and differences in prosocial moral reasoning between Brazilian and Anglo-American college students. Interam. J. Psychol. 33: 151-172.

Colby, A., and Kohlberg, L. (1987). The Measurement of Moral Judgment, Vol. 1: Theoretical Foundations and Research Validation. Cambridge University Press, Cambridge.

Crowne, D. P., and Marlowe, D. (1964). The Approval Motive. Wiley, New York.

Davis, M. H. (1983). Measuring individual differences in empathy: Evidence for a multidimensional approach. $J$. Pers. Soc. Psychol. 44: 113-126.

Davis, M. H., and Franzoi, S. (1991). Stability and change in adolescent self-consciousness and empathy. J. Res. Pers. 25: 70-87.

Eagly, A. H., and Crowley, M. (1986). Gender and helping behavior: A meta-analytic review of the social psychological literature. Psychol. Bull. 100: 283-308.

Eisenberg, N., Cameron, E., Tryon, K., and Dodez, R. (1981). Socialization of prosocial behavior in the preschool classroom. Dev. Psychol. 71: 773-782.

Eisenberg, N., Carlo, G., Murphy, B., and Van Court, P. (1995). Prosocial development in late adolescence: A longitudinal study. Child Dev. 66: 1179-1197.

Eisenberg, N., and Fabes, R. A. (1998). Prosocial development. In Damon W. (Series ed.) and Eisenberg, N. (Vol. ed.), Handbook of Child Psychology, Vol. 3: Social, Emotional, and Personality Development (5th edn.). Wiley, New York, pp. 701-778.

Eisenberg, N., Guthrie, I. K., Murphy, B. C., Shepard, S. A., Cumberland, A., and Carlo, G. (1999). Consistency and development of prosocial dispositions: A longitudinal study. Child Dev. 70: 1360-1372. 
Eisenberg, N., and Miller, P. (1987). The relation of empathy to prosocial and related behaviors. Psychol. Bull. 101: 91-119.

Fabes, R. A., Carlo, G., Kupanoff, K., and Laible, D. (1999). Early adolescence and prosocial/moral behavior I: The role of individual processes. J. Early Adolesc. 19: $5-16$.

Green, B., Shirk, S., Hanze, D., and Wanstrath, J. (1994). The Children's Global Assessment Scale in clinical practice: An empirical evaluation. J. Am. Acad. Child Adolesc. Psychiatry 33: 1158-1164.

Hoffman, M. L. (1982). Development of prosocial motivation: Empathy and guilt. In Eisenberg, N. (ed.), The Development of Prosocial Behavior. Academic Press, New York, pp. 218-231.

Hoffman, M. L. (1991). Empathy, social cognition, and moral action. In Kurtines, W. M., and Gewirtz, J. L. (eds.), Handbook of Moral Behavior and Development, Vol. 1: Theory. Erlbaum, Hillsdale, NJ, pp. 275-301.

Ickes, W., Stonson, L., Bissonnette, V., and Garcia, S. (1990). Naturalistic social cognition: Empathic accuracy in mixed-sex dyads. J. Pers. Soc. Psychol. 59: 730-742.

Iannotti, R. J. (1985). Naturalistic and structural assessments of prosocial behavior in preschool children: The influence of empathy and perspective taking. Dev. Psychol. 21: 46-55.

Johnson, R. C., Danko, G. P., Darvill, T. J., Bochner, S., Bowers, J. K., Huang, Y.-H., Park, J. Y., Pecjak, V., Rahim, A. R. A., and Pennington, D. (1989). Crosscultural assessment of altruism and its correlates. Pers. Indiv. Differ. 10: 855-868.

Kohlberg, L., and Candee, D. (1984). The relation between moral judgment and moral action. In Kurtines, W. M., and Gewirtz, J. L. (eds.), Morality, Moral Behavior, and Moral Development. Wiley, New York, pp. 52-73.

Kurdek, L. (1978). Perspective taking as the cognitive basis of children's moral development: A review of the literature. Merrill-Palmer Q. 24: 3-28.

Ladd, G. W., and Profilet, S. M. (1996). The Child Behavior Scale: A teacher-report measure of young children's aggressive, withdrawn, and prosocial behaviors. Dev. Psychol. 32: 1008-1024.

Maccoby, E. E., and Jacklin, C. N. (1974). The Psychology of Sex Differences. Stanford University Press, Stanford, CA.
Matthews, K. A., Batson, C. D., Horn, J., and Rosenman, R. H. (1981). Principles in his nature which interest him in the fortune of others: The heritability of empathic concern for others. J. Pers. 49: 237- 247.

Rest, J. (1983). Morality. In Mussen, P. (Series ed.) and Flavell, J. H., and Markman, E. (Vol. eds.), Handbook of Child Psychology, Vol. 3: Cognitive Development. Wiley, New York, pp. 556-629.

Rholes, W. S., and Bailey, S. (1983). The effects of level of moral reasoning in consistency between moral attitudes and related behaviors. Soc. Cogn. 2: 32-48.

Rushton, J. P., Chrisjohn, R. D., and Fekken, G. C. (1981). The altruistic personality and the self-report altruism scale. Pers. Indiv. Differ. 2: 1-11.

Rydell, A. M., Hagekull, B., and Bohlin, G. (1997). Measurement of two social competence aspects in middle childhood. Dev. Psychol. 33: 824-833.

Schroeder, D. A., Penner, L. A., Dovidio, J. F., and Piliavin, J. A. (1995). The Psychology of Helping and Altruism: Problems and Puzzles. McGraw-Hill, New York.

Schwartz, S. H. (1968). Words, deeds, and the perception of consequences and responsibility in social situations. $J$. Pers. Soc. Psychol. 10: 232-242.

Schwartz, S. H., and Howard, J. A. (1984). Internalized values as motivators of altruism. In Staub, E., BarTal, D., Karylowski, J., and Reykowski, J. (eds.), The Development and Maintenance of Prosocial Behavior: International Perspectives on Positive Development. Plenum, New York, pp. 229-255.

Selman, R. L. (1980). The Growth of Interpersonal Understanding: Developmental and Clinical Analyses. Academic Press, New York.

Staub, E. (1978). Positive Social Behavior and Morality: Social and Personal Influences, Vol. 1. Academic Press, New York.

Swisher, J. D., Shute, R. E., and Bibeau, D. (1985). Assessing drug and alcohol abuse: An instrument for planning and evaluation. Measur. Eval. Counsel. Dev. 17: 91-97.

Underwood, B., and Moore, B. (1982). Perspective taking and altruism. Psychol. Bull. 91: 143-173.

Weir, K., and Duveen, G. (1981). Further development and validation of the Prosocial Behavior Questionnaire for use by teachers. J. Child Psychol. Psychiatry Allied Disciplines 22: 357-374. 